\title{
Correction to: Preservation of connexin 43 and transzonal projections in isolated bovine pre-antral follicles before and following vitrification
}

\author{
Anniek Bus $^{1}$ (1) $\cdot$ Katarzyna Szymanska ${ }^{2,4} \cdot$ Isabel Pintelon $^{3} \cdot$ Jo L. M. R. Leroy ${ }^{1} \cdot$ Luc Leybaert $^{4} \cdot$ Peter E. J. Bols ${ }^{1}$ \\ Published online: 17 December 2020 \\ (C) Springer Science+Business Media, LLC, part of Springer Nature 2020
}

\section{Correction to: Journal of Assisted Reproduction and} Genetics

https://doi.org/10.1007/s10815-020-01993-2

The original article unfortunately contained a mistake. Prof. Luc Leybaert was not included in the author group.

The original article has been corrected.

The online version of the original article can be found at https://doi.org/ $10.1007 / \mathrm{s} 10815-020-01993-2$

Anniek Bus

anniek.bus@uantwerp.be

Katarzyna Szymanska

katarzyna.szymanska1188@gmail.com

Isabel Pintelon

isabel.pintelon@uantwerp.be

Jo L. M. R. Leroy

jo.leroy@uantwerp.be

Luc Leybaert

Luc.Leybaert@Ugent.be

Peter E. J. Bols

peter.bols@uantwerp.be
1 Faculty of Pharmaceutical, Biomedical and Veterinary Sciences, Laboratory of Veterinary Physiology and Biochemistry, Gamete Research Centre, University of Antwerp, Universiteitsplein 1, U building, 2610 Wilrijk, Belgium

2 Department of Obstetrics, Gynecology and Reproductive Sciences, Yale University School of Medicine, 310 Cedar Street, New Haven, CT 06510, USA

3 Faculty of Pharmaceutical, Biomedical and Veterinary Sciences, Laboratory of Cell Biology and Histology, University of Antwerp, Universiteitsplein 1, T building, 2610 Wilrijk, Belgium

4 Faculty of Medicine and Health Sciences, Department of Basic and Applied Medical Sciences (BAMS), Physiology group, Ghent University, C. Heymanslaan 10, B-9000 Ghent, Belgium 